\title{
Anesthetical Management of a Patient with Hereditary Muscle Sensory Neuropathy Type 2: Case of a 17-Year Old with Sacral Dermoid and a Short Overview of the Anesthesiological Considerations
}

\author{
Martin Lasičํ, Ana Lasič ${ }^{2}$, Caroline Oberleitner ${ }^{1}$, Fugger Claudia ${ }^{1}$, Ernst Trampitsch ${ }^{1}$ \\ ${ }^{1}$ Abteilungfür Anästhesiologie Und Intensivmedzin, LKH Villach, Villach, Austria \\ ${ }^{2}$ University Medical Centre Ljubljana, Ljubljana, Slovenia \\ Email: martin.lasic@gmail.com
}

How to cite this paper: Lasič, M., Lasič, A., Oberleitner, C., Claudia, F. and Trampitsch, E. (2021) Anesthetical Management of a Patient with Hereditary Muscle Sensory Neuropathy Type 2: Case of a 17-Year Old with Sacral Dermoid and a Short Overview of the Anesthesiological Considerations. Open Journal of Anesthesiology, 11, 25-32.

https://doi.org/10.4236/ojanes.2021.111003

Received: September 6, 2020

Accepted: January 23, 2021

Published: January 26, 2021

Copyright $\odot 2021$ by author(s) and Scientific Research Publishing Inc. This work is licensed under the Creative Commons Attribution International License (CC BY 4.0).

http://creativecommons.org/licenses/by/4.0/ (c) (i) Open Access

\begin{abstract}
We hereby present a short overview of the anaesthesiological considerations regarding the patient with Charcot-Marie-Tooth disease also known as hereditary muscle and sensory neuropathy, which affects peripheral nerves and muscles. Due to pathophysiology of the disease certain anaesthesiological complications associated with HMSN can be related. A case report describing protocol of the total venous anesthesia in the 17-year old patient operated on sacral dermoid with fistulae is presented. The patient recovered without any further complications. In the conclusion we would like to bring the importance of awareness to prepare the HMSN patient for a surgical procedure as well from anesthesiological as from surgical point of view to avoid possible unwanted event such as malignant hyperthermia, hyperkalemia, seizures, prolonged effect of muscle relaxants and worsening of the disease. As an important alternative to general anesthesia regional anesthesia should be considered.
\end{abstract}

\section{Keywords}

Hereditary Muscle Sensory Neuropathy Type 2, Anesthesia, Complications

\section{Introduction}

Muscle sensory neuropathy type 2, also known as Charcot-Marie-Tooth Syndrome, is the most common inherited neuropathy and it is more common in 
women than in men [1]. It affects about one in every 2500 people. HMNS is genetical disease that is associated with degeneration of select populations of motor and sensory neurons with accompanying atrophy and degeneration of their axons. Mostly myelinated axons are affected. Fibre degeneration and fibre loss progresses from distally to proximally. The clinical onset is often in first or second decade of life [2] and it includes peroneal and distal leg muscle wasting and weakness, distal sensory loss and areflexia [3]. Signs of sensory system dysfunction are common and include loss of vibration and joint position sense followed by decrease pain and temperature sensation in stocking and glove distribution. Neuropathic bone deformities develop including pes cavus (high-arched feet) and hammer toe. With further progression the hands become weak [2]. Hand muscles may be severely affected in the autosomnal and X-linked dominant forms [3]. Following further progression the severity of the disease worsens, and respiratory dysfunction may develop and become restrictive in nature [4]. Currently treatment of the disease consists only from supportive and surgical treatment because there is no effective drug treatment for the disease itself [5].

Regarding the anesthesia of such patients, possible malignant hyperthermia, hyperkalemia, seizures, prolonged effect of muscle relaxants and worsening of the disease should be taken in consideration.

The present case report describes anesthesia of a patient with HMNS type 2, who underwent the TIVA (Total Intravenous Anesthesia), for a short surgical procedure and the anaesthesiological considerations considering anesthesia of such patients.

\section{Case Report}

A 17-year old patient with hereditary muscle sensory neuropathy was brought to hospital for operation of sacral dermoid. He was diagnosed with HMSN 15 years ago. No follow ups to reevaluate the progression of disease at the neurologist were made. He already had the typical changes of the feet, which affected his gait but he was still able to walk. Also the fine movement of the arms was affected (troubled signing the consent to anesthesia). From the anaesthesiologic status there were no particularities. According to American society of Anesthesiology (ASA) his physical status was rated class 2 . The patient could open his mouth wide, his upper airway was classified with Mallampati 2, neck was not limited in movement. Spirometry showed lightly reduced vital capacity of the lung with no signs of obstruction.

For the anesthesia TIVA with 1\% Propofol and Fentanyl was chosen. Propofol was infused with TCI Schneider protocol that was started with $6 \mathrm{mcg} / \mathrm{ml}$. During the anesthesia it was reduced to $3.5 \mathrm{mcg} / \mathrm{ml}$. The sufficient analgesia was achieved with bolus of fentanyl $0.15 \mathrm{mg}$. The depth of anesthesia was monitored with BIS and it was held between 35 and 50. The medial arterial pressure was held at about $70 \mathrm{mmHg}$. Profenid was infused as antiphlogistic therapy at the beginning of the procedure. Additional antiemetic therapy was given in the form of On- 
dansetron and Dexamethason. During the procedure, which lasted about an hour, he received $500 \mathrm{ml}$ infusion of Elomel Isoton.

Open airway was achieved with Proseal supraglotical device. The mechanical ventilation was performed in pressure control mode with tidal volumes between $300-400 \mathrm{ml}$, frequency $14 / \mathrm{min}$ and maximal inspiration pressure of $8 \mathrm{~mm} \mathrm{H}_{2} \mathrm{O}$. Saturation was $97 \%$ at $50 \%$ inhaled Oxygen during the procedure.

After the operation spontaneously breathing patient was brought to recovery room. At admission Catapressan $150 \mathrm{mcg}$ was given as a treatment for the onset of tachycardia. The blood pressure was normal all the time. During the recovery course patient denied pains.

As the patient was fully recovered in one hour and was returned to ward.

The patient was followed up in the surgical outpatient clinic. There weren't any complications due to anesthesia reported.

Informed consent for publication was obtained.

\section{Discussion}

In discussion I would like to bring the topics that we considered important during anaesthetical management of such particular patient. In the foreground were taken most expected complications such as malignant hyperthermia, hyperkalemia, seizures, prolonged effect of muscle relaxants and worsening of the disease. In our opinion all the possible measures were taken in considerations to avoid the trigger factors that either can cause the acute complications or long term worsening of the disease.

First of all is the type of anaesthesia. The most commonly used inhalation anaesthesia was taken in discussion as a possible predisposing factor for the development of malignant hyperthermia. A clear trigger for malignant hyperthermia has not been defined. After reviewing described cases we have concluded that malignant hyperthermia could be triggered at any HMSN patient. Joseph F. Antognini reviewed anaesthesia of 86 patients with HMNS 2. He concludes that $90 \%$ of the patients received either Sevofluran and/or Succinylcholine as triggering factor. Complications other then malignant hyperthermia were present among $22 \%$ of the patients. Patients susceptible to hyperkaliemia following Succnylcholine developed arrhythmias-from subtile to malignant. Also hemodynamic changes, muscle weakness and pulmonary complications were described [6]. Individuals with certain neuromuscular disorders have long been suspected to have MHS (Malignant Hyperthermia Susceptibility). Due to small sample size of the patients with these disorders, who have developed one or more clinical symptoms of MH-like reactions during or after anesthesia, the anesthesiologists are confronted with the problem whether there is a $\mathrm{MH}$ or $\mathrm{MH}$-like reaction in patients with known neuromuscular disorders [7].

Therefore inhalation agents should be used with caution when dealing with patients with HMSN 2, while using TIVA may be a wiser choice.

Additionally there are also possible cardiac manifestations of the HMNS, mostly 
described by children with CMTD that underwent anesthesia and may include prolonged QT Syndrome, paroxysmal atrial flutter, cardiomyopathy, premature ventricular complexes (PVC) and a complete atrioventricular block [8] [9]. One of authors describes frequent PVC during an anesthesia with Thioenthal, Atracurium, nitrious oxide/oxygen and Halothan, at a child with plantar release procedure [9]. Also the inhalation anesthetic Sevoflurane has been reported to cause prolongation of the QT interval, and thus, it should be used with caution in patients with QT prolongation. To confirm increased incidence of these cardiac manifestations more research is required [5].

The second problem addressed is a choice of a muscle relaxant. It was not needed in our case, but should be chosen for possible use if the intubation should be performed. There are three possible known complications concerning use of the muscle relaxants. Firstly, the longer effect of the muscle relaxants that can be attributed to the loss of motor units. The latter shows itself in atrophy and muscle weakness. Simultaneous up-regulation of acetylcholine receptors in neuromuscular junction and increased sensitivity to these receptors occur [10]. Pulmonary impairment and the weakness of intercostal muscles and diaphragm may also be present [11]. When such findings are present, the prolongation of neuromuscular blocking agent should be expected. At comorbidities showing phrenic nerve and vocal cord dysfunction, the aspiration risk would be increased [5]. According to Joseph F. Antognini paralyzing dose of non-depolarizing agent was used in $45 \%$ of the cases. Most of the patients affected complained about "weakness" postoperatively, two patients developed pneumonia, of which one died due to it [6].

On the other hand the same effect, hence up-regulation of acetylcholine receptor will cause normal or even moderate resistance to the non-depolarizing muscle relaxants in patients in a state of chronic demyelination disease [5]. There is a significant positive correlation between the increase of acetylcholine receptors and the dose of non-depolarizing muscle relaxant [12]. Also should be taken in an aspect, that when using inhalation anesthetics, the neuromuscular blocking effect is prolonged in patients with HMSN, because this condition increases the neuromuscular blocking effect of the inhalational anesthetic itself [18]. Also aminoglycoside antibiotics, hypercarbia, acidosis, hypothermia, hypocalcemia and hypercalcemia may cause the prolongation of a neuromuscular blockade [5].

The neuromuscular monitoring is recommended, but instead of monitoring ulnar nerve, facial nerves are more appropriate due to the fact, that disease affects peripheral nerves [13]. The relaxation of the eye muscle corresponds well with relaxation of diaphragm [14].

The third problem that should be addressed at patients that are in chronic denervation state, is possible hyperkalemia as a consequence of malignant hyperthermia [15], which was discussed earlier, or at usage of defasciculating muscle relaxant. The latter occurs due to overexpressed isoform acetylcholine receptors, 
neuronal (nicotinic) alpha 7AChR, that are usually not active and preliminary evidences suggest, that they are up-regulated with either denervated states, injuries, at disuse atrophy and infection [16]. Despite these facts many authors do not take this complication as highly possible or problematic [6].

As a reversal of a muscle relaxation Sugammadex, a modified gamma - cyclodextrin, selective antagonist for steroidal neuromuscular blocking agents, such as vecuronium and rocuronium, was proven as an efficient drug for reversing moderate and deep neuromuscular block, also at high dosage of Rocuronium [17]. We should be also aware of possible side effects, such as rash, erythema, hypotension, wheezing and periorbital edema [19] [20]. There have been noticed possible QT prolongations and one case of atrioventricular block, nevertheless several larger studies have proven safety of the drug [21] [22] [23]. Otherwise medication has been successfully used for reversing neuromuscular blockade at the other myopathies (myasthenia gravis, dermatomyosis, Duchenne muscular dystrophie, spinal muscular atrophy, amyotrophic lateral sclerosis) [24]

In the option of anesthetical management of our patient was also taken the spinal anesthesia. There are few case reports describing use of spinal anesthesia at such patients [25] [26]. The 5\% Bupivacain injection was delivered with atraumatic $25 \mathrm{G}$ needle. The patient remained haemodynamically stable with oxygen saturation $91 \%$ on $50 \%$ Ventimask. No special complications that would suggest possible worsening of the patient's neurological condition were described [25]. With a thought, that the infection could be spread around the infected site, we decided to avoid spinal anesthesia and general anesthesia was used instead.

\section{Conclusion}

To conclude, we would like to emphasize the importance of proper preparation of the HMSN patient for a surgical procedure as well from anesthesiological as from surgical point of view. Important is preoperative status mostly to determine existing neurological deficits. In consideration the proper anesthesiological technic has to be planned. If it is possible, the regional anesthesia is a good choice. The right dosage of local anesthetic has to be chosen and under ultrasound guidance delivered at the right structure [27]. General anesthesia is also an option. TIVA would probably be in advantage over inhalation anesthesia due to possible complications that could arise during procedure even though many authors do not find them controversial [6]. Keeping in mind that at these patients postoperatively the prolonged neuromuscular blockade could be expected, there are not many doubts of using the Sugammadex as a reversal drug [21] [22] [23] [24].

\section{Authors and Affiliations}

OA Martin Lasič, Dr. Med., Abteilung für Anästhesiologie und Intensivmedzin, LKH Villach;

Ana Lasič, Dr. Med., University Medical Center Ljubljana; 
Ass. Dr. Caroline Oberleitner, Abteilung für Anästhesiologie und Intensivmedzin, LKH Villach;

OÄ Dr. Fugger Clauida, Abteilung für Anästhesiologie und Intensivmedzin, LKH Villach;

Prim Dr. Ernst Trampitsch, Abteilung für Anästhesiologie und Intensivmedzin, LKH Villach.

\section{Conflicts of Interest}

The authors declare no conflicts of interest regarding the publication of this paper.

\section{References}

[1] Braathen, G.J., Sand, J.C., Lobato, A., et al. (2011) Genetic Epidemiology of Charcot-Marie-Tooth in the General Population. European Journal of Neurology, 18, 39-48. https://doi.org/10.1111/j.1468-1331.2010.03037.x

[2] Szigeti, K. and Lupski, J.R. (2009) Charcot-Marie-Tooth Disease. European Journal of Human Genetics, 17, 703-710. https://doi.org/10.1038/ejhg.2009.31

[3] Hahn, A.F. (1993) Hereditary Motor and Sensory Neuropathy: HMNS Type II (Neuronal Type) and X-Linked HMNS. Brain Pathology, 3, 147-155.

https://doi.org/10.1111/j.1750-3639.1993.tb00739.x

[4] Mersiyanova, I.V., Ismailov, S.M., Polyakove, A.V., et al. (2000) Screening for Mutations in the Peripheral Myelin Genes PMP22, MPZ and Cx32 (GJB1) in Russian Charcot-Marie-Tooth Neuropathy Patients. Human Mutation, 15, 340-347. https://doi.org/10.1002/(SICI)1098-1004(200004)15:4<340::AID-HUMU6>3.0.CO;2 $\underline{-Y}$

[5] Kim, J.W., Choi, J.H., Kim, G., Ryu, K.H., Park, S.G., Jeong, C.Y. and Park, D.H. (2020) Anesthetic Management of Charcot-Marie-Tooth Disease. Archives of Clinical and Medical Case Reports, 4, 138-152. https://doi.org/10.26502/acmcr.96550179

[6] Antognini, J.F. (1992) Anaesthesia for Charcot-Marie-Tooth Disease: A Review of 86 Cases. The Canadian Journal of Anesthesia, 39, 398-400.

[7] Kim, D.-C. (2012) Malignant Hyperthermia. Korean Journal of Anesthesiology, 63, 391-401. https://doi.org/10.4097/kjae.2012.63.5.391

[8] Losito, L., De Rinaldis, M., Gennaro, L., et al. (2009) Charcot-Marie-Tooth Type 1a in a Child with Long QT Syndrome. European Journal of Paediatric Neurology, 13, 459-462. https://doi.org/10.1016/j.ejpn.2008.07.011

[9] Tetzlaff, J.E. and Schwendt, I. (2000) Arrhythmia and Charcot-Marie-Tooth Disease during Anesthesia. The Canadian Journal of Anesthesia, 47, 829. https://doi.org/10.1007/BF03019495

[10] Baraka, A.S. (1997) Vecuronium Neuromuscular Block in a Patient with Charcot-Marie-Tooth Syndrome. Anesthesia \& Analgesia, 84, 927-928.

https://doi.org/10.1213/00000539-199704000-00043

[11] Aboussouan, L.S., Lewis, R.A. and Shy, M.E. (2007) Disorders of Pulmonary Function, Sleep, and the Upper Airway in Charcot-Marie-Tooth Disease. Lung, 185, 1-7. https://doi.org/10.1007/s00408-006-0053-9

[12] Hogue, C.W. (1990) Resistance to D-Tubocurarine in Lower Motor Neuron Injury Is Related to Increase Acetylholine Receptors at the Neuromuscular Junction. Anes- 
thesiology, 73, 703-709. https://doi.org/10.1097/00000542-198909001-01203

[13] Pogson, D., Telfer, J. and Wimbush, S. (2000) Prolonged Vecuronium Neuromuscular Blockade Associated with Charcot Marie Tooth Neuropathy. British Journal of Anaesthesia, 85, 914-917. https://doi.org/10.1093/bja/85.6.914

[14] Hemmerling, T.M., Schmidt, J., Hanusa, C., et al. (2000) Simultaneous Determination of Neuromuscular Block at the Larynx, Diaphragm, Adductor Pollicis, Orbicularis Oculi and Corrugator Supercilii Muscles. British Journal of Anaesthesia, 85, 856-860. https://doi.org/10.1093/bja/85.6.856

[15] Wikipedia, Malignant Hyperthermia.

[16] Jeevendra Martyn, J.A., Richtsfeld, M. and Warner, D.O. (2006) Succinylcholine-Induced Hyperkalemia in Acquired Pathologic States: Etiologic Factors and Molecular Mechanisms. Anesthesiology, 104, 158-169.

https://doi.org/10.1097/00000542-200601000-00022

[17] Gold, S.J.A. and Harper, N.J.N. (2012) The Place of Sugammadex in Anaesthesia Practice. Trends in Anaesthesia and Critical Care, 2, 4-9.

https://doi.org/10.1016/j.tacc.2011.11.003

[18] Kim, J.W., Kim, G., Kim, T.W., Han, W., Maeng, J.H., Jeong, C.Y., Choi, J.H. and Park, D.H. (2019) Anesthesia in a Patient with Charcot-Marie-Tooth Disease with Pneumothorax: A Case Report. Journal of International Medical Research, 47, 5896-5902. https://doi.org/10.1177/0300060519881239

[19] Peeters, P.A.M., van den Heuvel, M.W., van Heumen, E., et al. (2010) Safety, Tolerability and Pharmacokinetics of Sugammadex Using Single High Doses (up to 96 $\mathrm{mg} / \mathrm{kg}$ ) in Healthy Adult Subjects: A Randomized, Double-Blind, Crossover, Placebo-Controlled, Single-Centre Study. Clinical Drug Investigation, 30, 867-874. https://doi.org/10.1007/BF03256915

[20] Menéndez-Ozcoidi, L., Ortiz-Gómez, J.R., Olaguibel-Ribero, J.M., et al. (2011) Allergy to Low Dose Sugammadex. Anaesthesia, 66, 217-219. https://doi.org/10.1111/j.1365-2044.2010.06611.x

[21] Cammu, G., De Kam, P.J., Demeyer, I., et al. (2008) Safety and Tolerability of Single Intravenous Doses of Sugammadex Administered Simultaneously with Rocuronium or Vecuronium in Healthy Volunteers. British Journal of Anaesthesia, 100, 373-379. https://doi.org/10.1093/bja/aem402

[22] Dahl, V., Pendeville, P.E., Hollmann, M.W., Heier, T., Abels, E.A. and Blobner, M. (2009) Safety and Efficacy of Sugammadex for the Reversal of Rocuronium Induced Neuromuscular Blockade in Cardiac Patients Undergoing Noncardiac Surgery. European Journal of Anaesthesiology, 26, 874-884. https://doi.org/10.1097/EJA.0b013e32832c605b

[23] de Kam, P.J., van Kuijk, J., Prohn, M., Thomsen, T. and Peeters, P. (2010) Effects of Sugammadex Doses Up to $32 \mathrm{mg} / \mathrm{kg}$ Alone or in Combination with Rocuronium or Vecuronium on QTc Prolongation: A Thorough QTc Study. Clinical Drug Investigation, 30, 599-611. https://doi.org/10.2165/11537210-000000000-00000

[24] Schaller, S.J. and Fink, H. (2013) Sugammadex as a Reversal Agent for Neuromuscular Block: An Evidence-Based Review. Core Evidence, 8, 57-67. https://doi.org/10.2147/CE.S35675

[25] Rodríguez, O.E., Martínez, E., Martín, J., Maiza, L. and Medina, J. (2019) Spinal Anesthesia in a Patient with Charcot-Marie-Tooth Disease Undergoing Orthopedic Surgery: Case Report. Colombian Journal of Anesthesiology, 47, 180-183. https://doi.org/10.1097/CJ9.0000000000000115 
[26] Roriz, D., Brandão, J., Ribas, D., Graça, R., Barros, J., Caramelo, S. and Abrunhosa, R. (2019) ESRA19-0292 Spinal Anesthesia in a Patient with Charcot-Marie Tooth Disease: A Case Report. Regional Anesthesia \& Pain Medicine, 44, A138.1-A138.

[27] Jacob, A.K., Kopp, S.L. and Hebl, J.R. (2015) Regional Anesthesia in the Patient with Preexisting Neurologic Disease. Regional Anesthesia \& Pain Medicine, 40, 467-478. 